\title{
"Difundir as luzes para o progresso": a expansão do Ensino Normal pela iniciativa municipal e particular em São Paulo (1927-1930)
}

"Disseminating the lights for progress": the expansion of Normal Education by the municipal and private initiative in São Paulo (1927-1930)

"Difundir las luces para el progreso": la expansión de la Escuela Normal por la iniciativa municipal y privada en São Paulo (1927-1930)

\author{
Leila Maria Inoue \\ Universidade Estadual Paulista Júlio de Mesquita Filho (Brasil) \\ https://orcid.org/0000-0002-3238-6396 \\ http://lattes.cnpq.br/4404113569573431 \\ leilinoue@yahoo.com.br \\ Ana Clara Bortoleto Nery \\ Universidade Estadual Paulista Júlio de Mesquita Filho (Brasil) \\ https://orcid.org/0000-0001-6316-3243 \\ http://lattes.cnpq.br/2576247757923028. \\ neryanaclara@gmail.com
}

\section{Resumo}

Neste artigo problematizamos o processo de expansão do Ensino Normal no estado de São Paulo a partir da Reforma da Instrução Pública de 1927 a 1930. Na busca de soluções para acabar com o analfabetismo, essa Reforma transformou o cenário educacional paulista, equiparando as Escolas Normais Livres às Escolas Normais Oficiais. Tal medida possibilitou que as associações particulares e os municípios criassem instituições para a formação de professores, devidamente reconhecidas pelo poder público, para formar professores para atender a demanda da escola primária. No recorte temporal selecionado observamos que, inicialmente, a expansão do Ensino Normal se deu principalmente pelas iniciativas municipais. Nosso objetivo é analisar as ações do estado e o papel do município nesse processo. Consideramos que as ações municipais, embora efêmeras, foram importantes para o processo de expansão do Ensino Normal possibilitando o protagonismo dos municípios em formar professores para atuarem nas regiões distantes das Escolas Normais Oficiais.

Palavras-chave: História da Formação docente. Ensino Normal. Escola Normal Livre. 


\begin{abstract}
The process of expansion of the Normal School in the state of São Paulo from the Reformation of Public Instruction between 1927 and 1930 is discussed. In search of solutions to end illiteracy, the Reform transformed São Paulo's educational scene by equating the Non-Official Normal Schools to Official Normal Schools. This measure made it possible for private associations and municipalities to create teacher-training institutions, duly acknowledged by the government, to train teachers to meet the demands of the Primary School. Current paper analyzes the activities of the state and the role of the municipalities in the process. Results show that, within the selected time frame, the expansion of Normal Schools was mainly due to municipal initiatives. Municipal activities were important for the expansion process of the Normal School, albeit ephemeral, allowing municipalities to be protagonists in forming teachers to act in distant regions out of reach of Official Normal Schools.
\end{abstract}

Keywords: History of teacher education. Normal School. Non-Official Normal School.

\title{
Resumen
}

En este artículo discutimos el proceso de expansión de la Educación Normal en el estado de São Paulo a partir de la Reforma de la Instrucción Pública de 1927 a 1930. En búsqueda de soluciones para terminar con el analfabetismo, esta Reforma transformó la escena educativa de São Paulo, equiparando las Escuelas Normales Libres a las Escuelas Normales Oficiales. Esta medida hizo posible que las asociaciones privadas y los municipios creasen instituciones de capacitación docente, debidamente reconocidas por el gobierno, para capacitar a los docentes para satisfacer la demanda de la escuela primaria. En el marco de tiempo seleccionado, observamos que, inicialmente, la expansión de la Educación Normal se debió principalmente a iniciativas municipales. Nuestro objetivo es analizar las acciones del estado y el papel del municipio en este proceso. Consideramos que las acciones municipales, aunque efímeras, fueron importantes para el proceso de expansión de la Escuela Normal, posibilitando el protagonismo de los municipios en la formación de maestros para actuar en las regiones distantes de las Escuelas Normales Oficiales.

Palabras clave: Historia de la formación de maestros. Escuela Normal. Escuela Normal Libre. 


\section{A formação de professores em São Paulo}

A formação de professores é uma temática largamente investigada, particularmente, no campo da História da Educação no Brasil. As instituições de formação - públicas e privadas e suas tipologias (Escola Normal, Escola Normal Livre, Escola Normal Rural e Escola Complementar) -, os saberes e práticas pedagógicos, as associações de professores, os alunos e suas agremiações, a arquitetura escolar e os materiais didáticos são objetos de investigação dessa temática.

O presente artigo $^{1}$ se ocupa de um momento singular em que as Escolas Normais Livres $^{2}$ passam a ser reconhecidas pelo poder público paulista. Foi por meio destas instituições que o estado ampliou o número de escolas de formação de professores a partir de 1927, com a implantação da Reforma da Instrução Pública, sob a orientação de Amadeu Mendes, Diretor Geral da Instrução Pública paulista ${ }^{3}$. Inoue (2015), ao analisar o processo de implantação de tais escolas, observou que alguns municípios protagonizaram essa experiência, independentemente de terem escolas primárias municipais. Mas, para sua manutenção, as Escolas Normais Livres, criadas e mantidas pelos municípios, cobravam mensalidades e taxa de matrícula, assim como as instituições criadas por associações particulares. As Escolas Normais Oficiais, criadas e mantidas pelo estado, cobravam apenas a taxa anual de matrícula conforme o Decreto $\mathrm{n}^{\circ} 4.600$, de 30 de maio de 1929, que regulamenta a Reforma de $1927^{4}$.

Visamos, com o presente artigo, analisar as ações do estado e o papel do município no processo de expansão da profissionalização docente. Para tanto, analisaremos as formas pelas quais o Ensino Normal no estado São Paulo se amplia a partir da Reforma de 1927, com a equiparação das Escolas Normais Livres às Escolas Normais Oficiais ${ }^{5}$. Para a construção da narrativa partimos de fontes privilegiadas como a legislação educacional (estadual e municipais), documentos oficias (Relatório do Diretor Geral e o Annuario do Ensino do estado de São Paulo), jornais (Correio Paulistano. O Estado de S. Paulo, O Linense e outros) e publicações como Um Retrospecto (1930), de autoria de João Lourenço Rodrigues, Poliantéia Comemorativa do Primeiro Centenário do Ensino Normal do estado de São Paulo (1946), O Ensino Secundário e Normal do Estado de São Paulo (1949). Além dessas fontes, dialogamos com os estudos que tomam as Escolas Normais Oficiais e Livres do estado de São Paulo, no recorte temporal. Portanto, a análise se fundamenta em Chartier, tomando o conceito de representação, segundo o qual uma dada realidade é construída "pelos interesses de grupo que as forjam. Daí, para cada caso, o necessário relacionamento dos discursos proferidos com a posição de quem os utiliza". (1990, p. 17). As fontes são analisadas a partir

\footnotetext{
${ }^{1}$ Parte destas reflexões resultam de pesquisa de Doutorado em Educação, realizada por Leila Maria Inoue, no Programa de Pós-Graduação em Educação, na linha de História e Filosofia da Educação Brasileira, da UNESP campus de Marília. A tese intitula-se Entre Livres e Oficiais: a expansão do Ensino Normal em São Paulo: 1927-1933. Foi orientada pela Professora Doutora Ana Clara Bortoleto Nery e defendida em 2015.

${ }^{2} \mathrm{O}$ termo livre refere-se às escolas que não eram oficiais, ou seja, estaduais. Era aplicado aos casos de escolas municipais e particulares. Naquele período os municípios não eram entes federados e nem responsáveis pelo ensino oficial e, portanto, precisavam do reconhecimento do Estado. Durante a pesquisa encontramos instituições denominadas Escola Normal Livre e Escola Complementar Livre.

${ }_{3}^{3}$ Amadeu Mendes formou-se na Escola Normal de Itapetininga, em 1899. Segundo Nery (2009, p. 104-105), ele era emergente do magistério público paulista e foi, por muitos anos, diretor do Ginásio de Campinas. Durante sua administração, uma de suas preocupações foi manter canais de comunicação e divulgação das atividades da Diretoria Geral da Instrução Pública. Desse modo, a Revista Escolar foi reestruturada e passou a denominar-se Educação, e os Anuários de Ensino não foram publicados em sua gestão, dando lugar aos Relatórios.

${ }^{4}$ As demais reformas da instrução pública paulista, de 1920 e 1925 , também determinavam o pagamento de taxa anual de matrícula nas Escolas Normais Oficiais e Escolas Complementares.

${ }^{5}$ A equiparação era uma medida nova na legislação do estado de São Paulo. Porém, já era adotada em outros estados da Federação como Rio de janeiro, Minas Gerais, Bahia, Pernambuco e Rio Grande do Sul (TANURI, 1979, p. 186).
} 
de sua natureza documental e dos sujeitos que a subscrevem, tendo em vista compreender os sentidos construídos para essa instituição que convencionou-se chamar Escola Normal Livre.

A Reforma de 1927 impulsionou a expansão do Ensino Normal pelos "novos núcleos urbanos paulistas" que se formavam com o avanço da cultura cafeeira e da imigração estrangeira pelo interior do estado. Em consequência, o número de Escolas Normais Livres aumentou significativamente superando o número de Escolas Normais Oficiais que permaneceram igual até o fim da década de $1930^{6}$. A lei atingiu ainda municípios de regiões que há tempos requeriam, junto ao poder estadual, escolas secundárias. A única exceção parece ser o município de Sorocaba que, com a equiparação, avançou quanto ao reconhecimento da instituição municipal já existente.

Ao analisarmos as novas regiões ${ }^{7}$ do interior do estado verificamos que a ampliação da instrução pública estava relacionada ao movimento de povoamento, de urbanização e de desenvolvimento de cada uma delas. Mas não só. Esteve, sobretudo, relacionado à força política local. Por isso, não é possível afirmar que a expansão ocorreu no mesmo ritmo em todas as regiões. A lei de 1927, através da equiparação de escolas particulares às escolas oficias, proporcionou aos novos núcleos urbanos contarem com professores primários formados pelas Escolas Normais Livres criadas nessas localidades.

O ensino particular fora objeto de regulamentação no final do século XIX ${ }^{8}$. Quanto à formação docente, o estado de São Paulo reconhecia apenas os títulos de estabelecimentos oficiais, constituídos pela Escola Normal da Capital e pelas Escolas Complementares. Os egressos das Escolas Normais Livres ${ }^{9}$ - no período anterior à equiparação - podiam exercer o magistério em escolas particulares e municipais ou concorrer às cadeiras provisórias como professores leigos. O primeiro projeto de lei que pretendeu equiparar as Escolas Normais Livres às Escolas Normais Oficiais é datado no ano de 1900 na Câmara dos Deputados do Estado de São Paulo, sem sucesso (TANURI, 1973, p. 252-253).

Ao analisarmos as medidas para ampliar a formação de professores no estado, para além da modelar Escola Normal da Capital, observamos três momentos:

$1^{\circ}$ transformação das Escolas Complementares em escolas de formação de professores (Reforma Gabriel Prestes, de 1895);

$2^{\circ}$ transformação das Escolas Complementares em Escolas Normais Primárias e Secundárias e criação de novas Escolas Normais (Reforma Oscar Thompson, em 1911);

$3^{0}$ equiparação das Escolas Normais Livres às Escolas Normais Oficiais (Reforma Amadeu Mendes, em 1927).

Partindo dessas observações, o presente artigo é sobre o $3^{\circ}$ momento. A equiparação das Escolas Normais Livres às Escolas Normais Oficiais, em 1927, foi justificada como medida de emergência para formar professores para escolas primárias localizadas em regiões distantes dos centros urbanos como as zonas rurais. Foi também muito criticada por representar, segundo algumas personalidades, a perda da qualidade da formação de professores. Contudo, nosso

\footnotetext{
${ }^{6}$ Segundo os dados que levantamos até o momento, apenas em 1938, após 14 anos desde a criação da última Escola Normal em São Paulo, foi criada a Escola Normal de Mococa, sob a égide do estado.

${ }^{7}$ Relativas às áreas que passam por processo de povoamento a partir das décadas iniciais dos anos de 1900.

8 A Lei $n^{\circ} 88$, de 08 de setembro de 1892 e o Decreto $n^{\circ}$ 144-B, de 30 de dezembro de 1892 já haviam regulamentado o exercício da iniciativa particular no setor do ensino em São Paulo.

${ }^{9}$ Mesmo sem o devido reconhecimento, algumas escolas de formação de professores foram fundadas em cidades paulistas como o Liceu Feminino Santista (1902) em Santos. Messenberg (2012) indica, sem muitas informações, a existência de uma Escola Normal Masculina em Sorocaba, onde Renato Sêneca de Sá Fleury lecionou em 1913. O Anuário de Ensino do estado de São Paulo de 1918, também indica, sem muitas informações, a existência do Externato Normal em São Paulo, localizado na rua Amaral Gurgel, $\mathrm{n}^{\circ}$ 22; do Externato Normal em Itapetininga e do Collegio Normal na cidade de Santa Rita.
} 
levantamento indica que, até a década de 1950, as iniciativas municipal e particular foram responsáveis pela expansão do Ensino Normal no estado de São Paulo.

No discurso oficial sobre a equiparação, as iniciativas particular e municipal foram chamadas a participar e cooperar com o governo estadual nessa "missão patriótica" de disseminar a instrução pública para combater o analfabetismo: difundir as luzes para o progresso. As luzes ${ }^{10}$ - metáfora largamente utilizada nos escritos da época ${ }^{11}$, na defesa da escolarização elementar - refere-se a luta contra o analfabetismo para vencer a ignorância (sombra) e alcançar a modernidade. Para a República, a escola era o símbolo da modernidade e através dela seria construído o progresso (CARVALHO, 2003). Tal qual Monarcha tomamos a metáfora neste estudo como a própria escola, neste caso, Escola Normal Livre.

Entretanto, questionamos as formas pelas quais a colaboração entre governo estadual, governos municipais e associações particulares ocorreu, haja vista a dificuldade que certos municípios enfrentavam para conseguir professores formados dispostos a lecionar em áreas de difícil acesso e as precárias condições orçamentárias em que se encontravam.

A Escola Normal, considerada símbolo da modernidade e do progresso sócio cultural (luz), é ressaltada nesse processo de formação de uma nova sociedade, pois seria a instituição formadora de professores para instruir a população analfabeta (sombra). Nesse sentido, a década de 1920 foi marcada por muitas reivindicações populares e de intelectuais pela melhoria e ampliação da escola primária. Tais reivindicações resultaram em diversas reformas da Instrução Pública ${ }^{12}$ que buscaram ampliar a instrução e acabar com o analfabetismo. Uma dessas reformas marca o terceiro momento de expansão da formação de professores acima referido - Reforma da Instrução Pública de 1927 - e proporcionou uma grande transformação no Ensino Normal paulista com o propósito de difundir também o ensino primário.

\section{As ações do poder estadual: a Reforma de 1927 e a equiparação da Escola Normal Livre}

A Reforma de 1927 pretendeu equalizar os problemas de escolarização no estado de São Paulo - sobretudo o analfabetismo - sem alteração significativa para além de equiparar as Escolas Normais Livres, suprimir cargos especiais de inspeção, aumentar "o número de Inspetores Distritais de 50 para 70 e" criar "o cargo de Inspetores Fiscais das Escolas Normais Livres, cujos vencimentos deveriam ser pagos, curiosamente, pelos estabelecimentos fiscalizados" (NERY, 2009, p. 102). A Reforma não causou polêmica que repercutisse na grande imprensa. Nas Escolas Normais Oficiais a Reforma reduziu de 5 para 3 anos o tempo de formação ${ }^{13}$. Tal medida, considerada de emergência pelo governo, objetivava formar professores em número suficiente aos cargos existentes, uma vez que a quantidade de professores leigos ${ }^{14} \mathrm{e}$ de escolas isoladas não providas pelo estado era elevado. Segundo Tanuri (1979, p. 187), uma mensagem presidencial do Presidente do estado Júlio Prestes, informava que, de 14 de julho de 1927 a 30 de julho de 1928, foram providas 2012 classes, sendo 889 por professores diplomados e 1.123 por leigos.

${ }^{10}$ Investigadores que procuram explorar está metáfora, especialmente, são: Denice Barbara Catani na tese Educadores à meia-luz (1989) e Carlos Roberto Monarcha na tese Escola Normal da Praça: o lado noturno das luzes (1994), ambas publicadas no formato de livro, respectivamente, em 2002 e 1999.

${ }^{11}$ Como no Relatório de Amadeu Mendes (1929), por exemplo.

12 Reforma Sampaio Dória (1920), Reforma Pedro Voss (1925) e Reforma Amadeu Mendes (1927).

${ }^{13}$ Essa redução não atingiu a Escola Normal da Capital, que permaneceu com sua estrutura organizada em 5 anos, implantada em 1925 pela Reforma Pedro Voss. Os professores formados nessa instituição gozavam de algumas regalias como: preferência para os cargos de diretores das Escolas Normais Primárias, Profissionais e Secundárias, professores de Escolas Complementares e Normais e Inspetores de ensino. Para Almeida (2016, p. 104), essa medida instaurou novamente uma duplicidade na formação de professores no estado.

14 Segundo Tanuri (1979, p. 187), a nomeação de professores leigos estava em desuso no estado desde meados da década de 1910 até 1925 quando voltou a ser usada. 
A justificativa para a equiparação era de que as 10 Escolas Normais Oficiais ${ }^{15}$ existentes naquele momento não formavam professores em número suficiente para atender a demanda, pois muitos diplomados não seguiam a carreira do magistério público e outros não se deslocavam para cidades e regiões de difícil acesso. Segundo Mendes (1929, p. 46),

As 10 escolas normais officiaes, diplomando uma média de 345 alumnos por anno, eram insuficientes para attender ás necessidades do ensino, pois para cumprir o encargo constitucional de fornecer instruccção gratuita ás 150.000 crianças em idade escolar e sem matricula nas zonas ruraes do Estado, devendo cada classe ter, em média 30 alumnos, seriam necessários 5.000 professores, número esse que as escolas officiaes só num prazo minimo de 6 anos poderiam dar.

Segundo dados apresentados por Amadeu Mendes o déficit fora causado pelo fato de que 2.156 escolas rurais foram criadas em 1926 e muitas delas estavam vagas por falta de professores. Em seu Relatório (1929), ele justifica a equiparação das Escolas Normais Livres citando uma fala de Júlio Prestes sobre os custos para manter as Escolas Normais Oficiais e a economia que as Normais Livres trariam para os cofres públicos.

As 10 escolas normais mantidas pelo Estado custavam anualmente 5.500:000\$000, o que demonstra que as escolas normaes livres, que devem produzir o mesmo resultado das escolas normaes officiaes, representam para o Estado, sem levar em conta as despesas de installação, uma economia de 14.3000:000\$000, que poderão ser applicados na disseminação do ensino primário. (MENDES, 1929, p. 58).

Para o Diretor Geral, para reduzir o analfabetismo era preciso ampliar o número de escolas primárias e provê-las com professores normalistas. Por outro lado, não havia consenso entre aqueles que se pronunciaram sobre a ampliação do número de Escolas Normais. Os participantes do Inquérito de $1926^{16}$, por exemplo, já haviam se manifestado contra a abertura de novas Escolas Normais no estado. Lourenço Filho ${ }^{17}$ e Fernando de Azevedo ${ }^{18}$, sucessores de Amadeu Mendes na Diretoria Geral da Instrução Pública e Diretoria Geral do Ensino, respectivamente, implantaram condições mais rigorosas a fim de conter as equiparações.

$\mathrm{O}$ fato é que com a equiparação muitas Escolas Normais Livres foram criadas em diversas cidades do estado - novos e antigos núcleos urbanos - com a validação do diploma. A equiparação transformou o cenário educacional paulista ao romper com o monopólio do estado.

As Escolas Normais Livres eram submetidas à fiscalização do governo estadual por meio dos Inspetores Fiscais. Segundo a Reforma de 1927, essas instituições deveriam atender algumas condições para que fosse concedida a equiparação: fundadas e mantidas por brasileiros; corpo docente integrado por professores brasileiros; cursos e programas em conformidade com os das Escolas Normais Oficiais; situadas em cidades onde não houvesse Escolas Normais Oficiais; lente de Pedagogia e Didática nomeado pelo estado; e possuir patrimônio mínimo de 200 Contos de Réis (SÃO PAULO, 1927).

${ }^{15}$ Escola Normal de São Paulo (conhecida como Escola Normal da Praça); Escola Normal de Itapetininga; Escola Normal de Piracicaba; Escola Normal de Campinas; Escola Normal de Guaratinguetá; Escola Normal de Pirassununga; Escola Normal de Botucatu; Escola Normal de São Carlos; Escola Normal da Casa Branca; Escola Normal do Braz (situada na capital).

${ }^{16}$ Organizado por Fernando Azevedo a pedido do jornal $O$ Estado de S.Paulo.

${ }^{17}$ Diretor Geral da Instrução Pública entre 1930 e 1931.

${ }^{18}$ Diretor Geral da Instrução Pública entre 1932-1933. 
As condições para a equiparação das Escolas Normais Livres demonstram o controle do poder público estadual sobre o funcionamento e a formação pedagógica dessas instituições. $\mathrm{O}$ professor de Pedagogia e Didática - ao que tudo indica, professor formado em alguma Escola Normal Oficial - seria nomeado pelo governo como forma de garantir, mas também fiscalizar, que a formação pedagógica fosse o mais próximo possível daquela ofertada pelas Normais Oficiais.

Sobre a nomeação do professor e Pedagogia e Didática, o jornal Correio Paulistano (1930, p. 5) noticiou que o professor Antônio d'Ávila fazia parte do corpo docente da Escola Normal Livre de Santa Cruz do Rio Pardo como professor de Psicologia, Didática e Desenho. Trevisan (2007, p. 25) alude que Antônio d'Ávila formouse normalista na Escola Normal de São Paulo em 1920. Iniciou sua carreira justamente na região de Santa Cruz do Rio Pardo, em 1921, passando por várias escolas e cargos até ser nomeado professor da Escola Normal Livre de Santa Cruz do Rio Pardo.

Na Escola Normal Livre de Sorocaba, Almeida (2015) indica que o professor Renato Sêneca de Sá Fleury - formado pela Escola Normal de São Paulo em 1912 - participou da criação do Ginásio Municipal e da Escola Normal Livre de Sorocaba, onde lecionou Pedagogia, Psicologia e Didática e outras matérias por 14 anos, desde a fundação da Escola até sua aposentadoria em 1942. Segundo Messenberg (2012, p. 57-58), após a Revolução de 1930, Renato Fleury foi exonerado pelo prefeito do seu cargo na Escola Normal Livre de Sorocaba, mas em 1931, prestou concurso e atuou como Inspetor Fiscal dessa mesma instituição. Com a Reforma Fernando de Azevedo (1933), assumiu a chefia da seção de Educação e voltou a ministrar as aulas de Pedagogia, Psicologia e Didática.

Bruschi (2005) alude que na Escola Normal Livre de Itápolis as aulas Pedagogia, em 1933, estavam sob responsabilidade do professor Arcipestre Rugeri. Buscamos informações sobre esse professor no Livro Jubilar da Escola Normal da Capital, de João Lourenço Rodrigues (1930, p. 212), e encontramos que ele se formou normalista na Escola Normal de Pirassununga em 1923. Assim, esses são indícios de que essa condição era cumprida ${ }^{19}$.

Outra medida prevista pela Reforma era a impossibilidade de equiparação de duas Escolas Normais Livres em regime de internato ou externato no mesmo município. As escolas equiparadas deveriam também depositar, a cada seis meses, na Coletoria Estadual, o valor correspondente aos vencimentos anuais do Inspetor Fiscal e do professor de Pedagogia e Didática (SÃO PAULO, 1927).

O controle se estendia aos professores diplomados pelas Escolas Normais Livres. Eles poderiam lecionar em uma escola urbana somente depois de passar 200 dias letivos em exercício em escolas rurais e poderiam ser professores de grupos escolares após 200 dias letivos de exercício em escolas urbanas ou 400 dias em escolas rurais. A exigência não se estendia aos diplomados pelas Normais Oficiais (SÃO PAULO, 1927). Mais do que hierarquizar os diplomas, essa determinação era uma tentativa de se fazer cumprir os propósitos de Amadeu Mendes de prover as escolas primárias de difícil acesso com professores formados.

Um ponto que precisa ser considerado para compreender a História da Formação Docente é a precária condição física e pedagógica das Escolas Normais, mesmo as Oficiais. Sobre as Escolas Normais Livres há referências de que em algumas localidades foram feitas campanhas para a arrecadação financeira ${ }^{20}$ para garantir seu funcionamento, como indica Bruschi (2005) em sua dissertação sobre a Escola Normal Livre de Itápolis e Almeida (2015) em sua tese sobre a Escola Normal Livre de Sorocaba.

O controle das Escolas Normais Livres tornou-se mais rigoroso ainda na gestão de Amadeu Mendes. O Decreto $\mathrm{n}^{\circ}$ 4. 600, de 1929, que regulamentou a Reforma de 1927,

\footnotetext{
${ }^{19}$ Alguns trabalhos discutidos neste artigo indicam o nome do professor de Pedagogia e Didática, mas, até a finalização deste artigo, não conseguimos encontrar mais informações sobre eles.

${ }^{20}$ A arrecadação financeira para ajudar instituições educativas certamente é realizada até os dias atuais, porém, neste artigo, estamos buscando dados sobre as Escolas Normais Livres, especialmente as municipais, criadas entre 1927 a 1933.
} 
determinou condições mais rigorosas para a equiparação a fim de garantir a qualidade do ensino conforme as exigências da Diretoria Geral da Instrução Pública.

$\mathrm{O}$ aumento no número de Escolas Normais Livres preocupou os educadores e legisladores em relação a qualidade do ensino. Com a saída de Amadeu Mendes, o professor Lourenço Filho (1930-1931) assumiu a da Diretoria Geral da Instrução Pública e suspendeu a equiparação de todas as Escolas Normais Livre. Segundo Peres (1966, p. 14), durante sua gestão, Lourenço Filho procurou "cassar a equiparação das Escolas Normais Livres para sujeitá-las a disposições legais mais rigorosas e eficientes, dando-lhes uma organização mais condizente com os interesses do ensino".

Além de se submeterem à fiscalização, o Decreto $n^{\circ} 4$. 794, de dezembro de 1930, determinou que para uma Escola Normal Livre obter a equiparação deveria ser fundada e mantida por associações nacionais ou municipais; dirigida por brasileiros; seguir os programas das Escolas Normais Oficiais; funcionar em prédio que atendam as condições higiênicas e pedagógicas; possuir mobiliário adequado, gabinete de ciências fisiconaturais, biblioteca especializada e material didático; manter curso primário anexo para a prática pedagógica; arcar com as despesas dos exames de admissão e demais exames do curso que serão prestados perante bancas nomeadas pelo governo; ter no mínimo 15 alunos por classe; depositar no Tesouro do Estado, para que fosse autorizada a abertura das aulas, a importância de 14:400\$000 (quatorze contos e quatrocentos mil réis) para o pagamento do professor fiscal (São Paulo, 1930).

Com as medidas mais rigorosas implantadas na gestão de Lourenço Filho, algumas Escolas Normais Livres fecharam as portas. Porém, ainda não encontramos documentos sobre como ocorreu o encerramento das atividades dessas escolas. No Anuário de Ensino do estado de São Paulo (19351936), consta que das 51 Escola Normais Livres que funcionavam em 1930, apenas 48 voltaram a requerer a equiparação do seu ensino, mas somente 35 delas obtiveram.

Em 1930, formavam-se as primeiras turmas de professores das Escolas Normais Livres. Segundo Rodrigues (1930, p. 316-317), essas escolas formaram 816 professores, enquanto as Escolas Normais Oficiais formaram 1.167 professores. Mesmo em menor número, a Escola Normal Oficial formou naquele ano mais professores do que as demais.

Essa pode ser a razão pela qual os professores leigos foram exonerados durante a gestão de Lourenço Filho pelo Decreto n ${ }^{\circ}$ 4.780, de 28 de novembro de 1930. No Annuario de Ensino do estado de São Paulo (1935-1936) também consta que Lourenço Filho dispensou cerca de 1.044 professores leigos durante sua gestão, assim como Souza (2009, p. 187) alude que,

No âmbito da racionalização e moralização do serviço público, o diretor exonerou todos os professores leigos contratados a partir de 1927 (1.044 professores), procedendo à revisão da localização das escolas vagas do estado e abrindo concurso público para professores diplomados. A medida, que suscitou grande polêmica e descontentamento dos professores, foi justificada pelo diretor do ensino como iniciativa tomada a bem do interesse do ensino visando eliminar anomalias verificadas, como o favoritivismo político, interferindo na localização de escolas e nomeação de professores sem adequação às necessidades do sistema escolar e o favorecimento de professores leigos em detrimento dos profissionais qualificados.

O jornal O Estado de S.Paulo também noticiou em 30 de novembro de 1930 (p. 4) a dispensa de todos os professores leigos admitidos, como medida de emergência, pela Reforma de 1927. De acordo com a notícia o "Governo Provisório decidiu hontem a dispensa de todos os professores leigos, que regiam escolas urbanas e ruraes no Estado". 
Contudo, apesar do receio dos educadores e das medidas mais rigorosas para a equiparação das Escolas Normais Livres, sua expansão se deu por volta da década de 1950, quando inicia, ao final de 1951, a expansão dos Institutos de Educação pelo interior do estado $^{21}$. Sendo assim, a "medida de emergência", implantada em 1927, perpetuou por muitas décadas e foi uma oportunidade de estudos para rapazes e moças, especialmente nos novos centros urbanos onde ainda não havia escolas de Ensino Secundário.

\section{As Escolas Normais Livres sob a participação municipal}

As reivindicações por instalação de escolas públicas nas diversas localidades nas décadas iniciais do século XX tinham por foco, além das escolas primárias, escolas de formação de professores (DINIZ; SOUZA, 2019, p. 98). Tais reinvindicações podem ter contribuído para equiparação dessas instituições. Sendo assim, as ações dos poderes municipais foram significativas para o processo de expansão do Ensino Normal. Para um olhar cuidadoso, consideraremos as particularidades de cada região.

Na região oeste ${ }^{22}$ paulista, na cidade de Lins, o jornal $O$ Linense $^{23}(1928$, p. 2) publicou a seguinte nota sobre a criação da Escola Normal Livre de Lins em 14 de maio de 1928:

Sabemos que membros influentes da nossa sociedade, e políticos de destaque cogitam a fundação de uma Escola Normal Livre, com o concurso da municipalidade.

A idéa é digna dos maiores louvores, pois que é uma necessidade cujos benefícios se comprehendem immediatamente, estando a nossa cidade em condição previlegiada para esse fim, sendo como é um centro único, na expressão geographica, desta zona.

Os autores dessa grande idéa, realizando-a, ligarão seu nome perpetuamente a historia de Lins, como seus benfeitores.

Os nossos applausos a tão nobre concepção e nossos votos pela sua breve organização.

A nota do jornal $O$ Linense constrói uma narrativa a favor da criação da Escola Normal Livre em Lins pela ação do poder político local. A Escola Normal representava progresso em uma região onde o desenvolvimento estava incipiente e, para chegar ao auge, não poderiam faltar escolas e professores para atender a população que se ampliava. A notícia evidencia que havia expectativa pela criação da Escola Normal Livre de Lins. Essa instituição foi mantida pelo município até 1938 e depois foi transferida para o Colégio Diocesano com a denominação de Escola Normal Livre Nossa Senhora Auxiliadora e se tornou o Departamento Feminino do Ginásio ${ }^{24}$. As dificuldades financeiras da municipalidade em manter a escola foi a razão para a transferência da instituição para o setor particular.

Na cidade de Santa Cruz do Rio Pardo, não encontramos evidências concretas sobre as reivindicações pela criação da Escola Normal Livre. Como em outras localidades, o reconhecimento da importância dessa instituição para o desenvolvimento cultural e também econômico foi manifestado nos jornais locais. A Escola Normal Livre de Santa Cruz do Rio Pardo foi criada pelo poder municipal em $1928^{25}$ e suas atividades iniciaram-se em 1929. Foi

\footnotetext{
${ }^{21}$ Conforme indica Labegaline (2005).

22 As Escolas Normais Livres da região oeste paulista foram o objeto de estudo da tese Entre Livre e Oficiais: a expansão do Ensino Normal em São Paulo (1927-1933).

23 Jornal publicado na cidade de Lins/SP.

${ }^{24}$ O Ginásio Diocesano de Lins era destinado apenas para rapazes, enquanto a Escola Normal era apenas para moças.

${ }^{25}$ Lei Municipal $n^{\circ}$ 429, de 25 de agosto de 1928 - (Ata da Câmara Municipal).
} 
transformada em Escola Normal Oficial de Santa Cruz do Rio Pardo em 06 de junho de 1939. A formatura da primeira turma de normalistas da Escola Normal Livre de Santa Cruz do Rio Pardo foi noticiada pelo Santa Cruz Jornal.

-"No corrente anno sahirá a primeira turma de professores".

-"Dezena e meia de moças receberão o diploma - o mais honroso, no magisterio de nossa terra - elevando o nome do Estabelecimento e disseminando o que aprenderam, por essas cidades alem".

-"Por que razão a Escola Normal não será sempre o patrimonio social da nossa cidade, ou viveiro dessas intelligencias moças que vicejam no municipio"? (Ano I - no 1, 29/05/19[31], p. 1, apud PRADO; SATO, 2013).

Há um indicativo na matéria de que havia algum problema relacionado à continuidade das atividades da Escola Normal. Todavia, não encontramos mais informações.

Em Bauru, a iniciativa municipal também foi importante para a criação ${ }^{26}$ da primeira instituição de formação de professores da cidade, denominada Escola Normal Livre Gomes Duarte. Contudo, logo em 1929 o município transferiu a Escola Normal para uma instituição particular denominada Ginásio Guedes de Azevedo. Essa instituição foi extinta e nenhum dado foi localizado no arquivo - que se encontra na Diretoria de Ensino de Bauru -, referente às décadas de 1920 e 1930, que pudesse elucidar melhor a questão ${ }^{27}$.

Seguindo os indícios e observando a trajetória de outras Escolas Normais Livres paulistas, levantamos a hipótese de que as Escolas Normais Livres de Santa Cruz do Rio Pardo, Lins e Bauru enfrentaram dificuldades financeiras para a manutenção das atividades e, consequentemente, foram transferidas para cargo do estado e de outras instituições educativas particulares já existentes. Os municípios já investiam parte dos recursos provenientes da arrecadação na aquisição de terrenos e construção de prédios para os Grupos Escolas e escolas isoladas, tal qual relatado em alguns artigos (Honorato; Nery, 2019, Diniz; Souza, 2019). Outros mantinham escolas primárias municipais (Sandano, 2009). Daí, possivelmente, a dificuldade em manter uma instituição específica.

Outras pesquisas evidenciam o importante papel dos municípios paulistas no processo de expansão do Ensino Normal. Na cidade de Araraquara a Escola Normal Livre Mackenzie também foi criada e mantida pelo município por pelo menos uma década. Em 1926, o município assumiu a administração de um colégio particular que passou a denominar-se Gymnasio Municipal Mackenzie de Araraquara. Em 1928, foi instalada a Escola Normal, anexa a esse ginásio. Segundo Antonio e Souza (2014), não se sabe ao certo a data de seu fechamento, porém, os indícios apontam que o último ano de seu funcionamento foi em 1939.

A Escola Normal Livre de Itápolis foi criada pela Lei Municipal $n^{\circ}$ 85, em 30 agosto de 1929 e equiparada no mesmo ano. A imprensa local noticiou com entusiasmo a nova instituição que beneficiaria a população da região e traria a cidade de Itápolis o selo da modernidade cultural.

A Câmara Municipal anuncia a aprovação do "relevante projeto dos vereadores Eugênio de Paula e Venâncio de Oliveira Machado", autorizando a criação da Escola Normal Livre de Itápolis, sob o imediato patrocínio da Câmara Municipal. (O JORNAL DE ITÁPOLIS, 17/08/1929, p. 2, apud BRUSCHI, 2005, p. 53).

\footnotetext{
${ }^{26}$ Lei Municipal $n^{\circ} 279$, de 25 de fevereiro de 1928.

${ }^{27} \mathrm{O}$ arquivo da Diretoria de Ensino de Bauru foi visitado durante a realização da pesquisa de Doutorado em Educação realizada entre 2011 e 2014. O resultado dessa pesquisa é a tese intitulada Entre Livres e Oficiai: a expansão do Ensino Normal em São Paulo (1927-1933).
} 
Segundo Bruschi (2005), apesar das dificuldades e das interrupções das atividades, a Escola Normal Livre de Itápolis foi mantida pela municipalidade até o ano de 1947, quando foi oficializada pelo governo estadual.

Os trabalhos de Lima (2005), Sandano (2009) e Almeida (2015) sobre a Escola Normal Livre de Sorocaba evidenciam que a população sorocabana, desde os primeiros anos do século XX, reivindicava a criação de uma instituição de formação de professores para atender as necessidades locais. Contudo, a instalação da Escola Normal se concretizou somente com a Reforma de 1927, por iniciativa municipal ${ }^{28}$. Embora essa instituição tenha passado por adversidades indicadas por Almeida (2015) como prédios adaptados, falta dos laboratórios necessários à formação docente conforme as exigências da legislação paulista e dificuldades financeiras, ela se manteve ativa de 1929 a 1967 pela prefeitura municipal. Em 1967 foi transformada em Instituto Educacional Municipal Dr. Getúlio Vargas. A imprensa local noticiou a criação da Escola Normal Livre de Sorocaba com entusiasmo.

Três notáveis melhoramentos para Sorocaba- Graças aos esforços dos políticos situacionistas, que em boa hora assumiram a direção de Sorocaba e a boa vontade do povo, que deu apoio às nobres iniciativas do diretório a nossa terra que já desfruta a grande vantagem do Ginásio Municipal, que vai em franco progresso, contará em breve com mais dois notáveis melhoramentos. São eles a Escola Normal Livre o a Escola Profissional. A Escola Normal Livre, que funcionará anexa ao Ginásio iniciará seu funcionamento a $1^{\circ}$ de fevereiro do ano vindouro, sendo que oportunamente será anunciada a abertura de inscrições para o exame de admissão. Devidamente autorizados pelo diretório podemos informar aos interessados que convém iniciar desde já o preparo dos candidatos para haver tempo de se apresentarem a exame, podendo, nesse sentido, se entenderem com o Sr. João Machado de Araújo, digno diretor do Ginásio. Logo que nossos edis tomarem posse dos cargos dar-se-á a municipalização do Ginásio e Normal que também será reconhecida pelo governo estadual. (JORNAL CORREIO DE SOROCABA, 11/11/1928, apud ALMEIDA, 2015, p. 71-72).

Sorocaba assim se destacava pelo forte investimento municipal no Ensino Secundário por meio do Ginásio e da Escola Normal Livre.

Outras pesquisas que se dedicaram ao estudo de Escolas Normais Livres mantidas por associações particulares ou ordens religiosas evidenciam as postulações pela criação de Escolas Normais devidamente equiparadas em diversas cidades. Mas é importante elucidar para a compreensão do papel dos municípios no processo de expansão do Ensino Normal que, embora certas escolas fossem criadas e mantidas por associações particulares ou por ordens religiosas ${ }^{29}$, não é possível excluir o envolvimento de parte do governo municipal na criação e manutenção delas.

Em Ribeirão Preto, localizada em uma região desenvolvida do estado de São Paulo, a imprensa local noticiou que

Ribeirão Preto é a única cidade do interior onde se torna absolutamente imprescindível a criação de uma escola normal por mil razões que já temos exposto e que não podem razoavelmente ser contestadas. A despeito de se tratar de uma palpitante necessidade, o governo sempre recusou este mesquinho benefício ao município que mais contribui para as rendas do Estado. (JORNAL "A CIDADE", 09/10/1911, p.1, apud FURTADO, 2007, p. 70).

\footnotetext{
${ }^{28}$ Lei Municipal $n^{\circ} 209$ - Projeto ${ }^{\circ} 01$, de 16 de janeiro de 1929.

${ }^{29}$ Como a ordens mantidas pela Igreja Católica como Irmãs Salesianas ou as Irmãs do Sagrado Coração de Jesus.
} 
Apesar das postulações, a primeira Escola Normal só foi instalada em 1928, pela Associação do Ensino de Ribeirão Preto ${ }^{30}$, e a segunda instituição foi criada em 1930, anexa ao Colégio Santa Úrsula, mantido pela Congregação Francesa das Ursulinas (ordem religiosa da Igreja Católica). Segundo Furtado (2007), todas essas instituições eram particulares, sendo a primeira mista e a segunda feminina.

Em Santos, também localizada em uma região desenvolvida, Nascimento (2016, p.55) indica que pelo menos desde 1914 aconteciam discussões sobre a criação de uma Escola Normal Oficial na cidade. No entanto, na falta de uma instituição oficial, as Escolas Normais Livres foram responsáveis por formar os professores da região santista como o Liceu Feminino Santista, criado em 1902 pela Associação Feminina Beneficente e Instrutiva ${ }^{31}$ e a Escola Normal Livre de Santos, criada e mantida pela Associação Instrutiva José Bonifácio, em 1928.

Segundo Nascimento (2016, p. 48), a criação da Associação Instrutiva José Bonifácio - que mantinha a Escola Normal Livre de Santos - está ligada à extinta Escola do Comércio (1907-1917) fundada e mantida pela prefeitura de Santos. Contudo, apesar da extinção da Escola do Comércio, o Parecer n.159/1917, da Câmara Municipal evidencia as subvenções do município para a Escola Normal Livre de Santos.

Em sua Dissertação sobre o Liceu Feminino Santista, Campos (2018) confirma que o Liceu foi a primeira instituição de formação de professores na cidade de Santos fundada em 1902. A Associação Feminina Beneficente e Instrutiva também fundou e manteve escolas maternais para crianças carentes e o Liceu era voltado para a educação feminina e formação de professoras para essas escolas, uma vez que havia falta de professores na cidade. O Liceu Feminino também recebia subvenções municipais e estaduais para custear sua manutenção e além das alunas carentes recebia também as alunas da elite santista devido ao prestígio que conquistou (p. 41). Devido às dificuldades financeiras, ele manteve a gratuidade até 1930, quando passou a cobrar taxas de matrícula e mensalidades das famílias que tinham condições financeiras para pagar pelos estudos das filhas. O primeiro pedido de equiparação do Liceu Feminino Santista à Escola Normal de São Paulo foi enviado ao Congresso do Estado em 1905. Contudo, segundo a autora, a equiparação não foi obtida mesmo com a Reforma de 1927. A legislação determinava que somente uma Escola Normal Livre poderia ser equiparada em cada município em regime de internato ou externato e a Escola Normal Livre de Santos, criada e mantida pela Associação Instrutiva José Bonifácio, já havia obtido a equiparação nesse momento. As alunas egressas do Liceu poderiam lecionar nas escolas municipais de Santos, porém, como a instituição não era equiparada, as matrículas diminuíram e a formação de professores foi encerrada em $1939^{32}$.

Com a implantação da Reforma de 1927, no início do ano de 1928, 26 Escolas Normais Livres - 2 na Capital e 24 no interior - foram equiparadas e instaladas superando o número das Escolas Normais Oficiais. Em 1929, 08 Escolas Normais Livres foram equiparadas e em 1930, 04 escolas. O estado passou a ter 48 Escolas Normais no total - 10 Escolas Normais Oficiais e 38 Escolas Normais Livres ${ }^{33}$.

O Quadro 1 a seguir apresenta um levantamento das Escolas Normais Livres municipais criadas entre 1928 a 1930 redigido ao longo da pesquisa ${ }^{34}$.

\footnotetext{
${ }^{30}$ Atual UNAERP - Universidade de Ribeirão Preto.

31 Essa associação, fundada em 1902, foi idealizada pela educadora Anália Franco e pela professora normalista Eunice Caldas e coordenada por um grupo de mulheres da elite econômica e política da cidade de Santos. Essa associação era de caráter assistencialista, mantida por doações dos sócios beneméritos e subvenções municipais e estaduais.

${ }^{32} \mathrm{O}$ Liceu ainda existe na cidade de Santos, oferece todas as modalidades do ensino básico.

${ }^{33}$ Nenhuma Escola Normal Oficial foi criada nesse período. Ver levantamento completo em Inoue (2015).

${ }^{34}$ É importante esclarecer que não pretendemos apontar um número exato de Escolas Normais Livres municipais, mas socializar informações recolhidas em anos de pesquisa. Devido à falta de fontes oficiais e de trabalhos científicos, algumas dessas informações que compõem do Quadro 1 foram confirmadas em almanaques (online) ou blogs memorialísticos que visam reconstituir a história das respectivas cidades paulistas e notícias disponíveis online.
} 
Quadro 1 - Escolas Normais Livres Municipais paulistas (1928-1930)

\begin{tabular}{|c|c|}
\hline \multicolumn{2}{|c|}{ Escolas Normais Livres Municipais paulistas criadas entre (1928-1930) } \\
\hline Escola/Localização & Informações/Dados \\
\hline $\begin{array}{l}\text { Escola Normal Livre do Liceu Rio Branco, } \\
\text { de Catanduva }\end{array}$ & $\begin{array}{l}\text { - Lei Municipal } n^{\circ} 157 \text {, de } 09 \text { de junho de } 1928 \\
\text { - Transformada em Escola Normal Oficial em } 1939 \\
\text { pelo Decreto } n^{\circ} 10.317 \text {. }\end{array}$ \\
\hline Escola Normal Livre de Tietê & $\begin{array}{l}\text { - Foi criada pela Lei 112, sancionada pelo então } \\
\text { prefeito de Tietê, Delphino Martins Bonilha, e } \\
\text { aprovada pela Câmara Municipal em } 2 \text { de janeiro } \\
\text { de } 1928 \text {. } \\
\text { - Instalada oficialmente em 31/03/1928 pela } \\
\text { Prefeitura Municipal } \\
\text { - Transformada em Escola Normal Oficial em } 1939 .\end{array}$ \\
\hline Escola Normal Livre de Taquaritinga & $\begin{array}{l}\text { - Criada em 04/10/1928 por uma Associação } \\
\text { particular e depois encampada pelo Município. } \\
\text { - Em 09/07/1945, foi transformada em Escola } \\
\text { Normal e Ginásio Oficial de Taquaritinga. }\end{array}$ \\
\hline $\begin{array}{l}\text { Escola Normal Livre Gomes Duarte, de } \\
\text { Bauru }\end{array}$ & $\begin{array}{l}\text { - Criada pelo Município de Bauru; } \\
\text { - Transferida em 13/05/1928, para o Ginásio } \\
\text { Guedes de Azevedo (particular) }\end{array}$ \\
\hline Escola Normal Livre Municipal de Mirassol & $\begin{array}{l}\text { - Criada pelo Decreto Municipal no 62, de } \\
\text { 01/12/1928; } \\
\text { - Equiparada em 03/01/1929. }\end{array}$ \\
\hline Escola Normal Livre de Franca & $\begin{array}{l}\text { - Criada em 15/01/1928 pelo então prefeito Major } \\
\text { Torquato Caleiro; } \\
\text { - Equiparada em 20/02/1928. } \\
\text { - Foi oficializada em 1941, pelo Decreto Estadual } \\
\text { 11.839, de } 7 \text { de fevereiro. }\end{array}$ \\
\hline Escola Normal Livre de São Simão & $\begin{array}{l}\text { - Criada pela Prefeitura de São Simão } \\
\text { - Equiparada em 20/02/1928. }\end{array}$ \\
\hline Escola Normal Municipal de Taubaté & $\begin{array}{l}\text { - Criada em } 1929 \text { pelo Decreto Municipal n } 262 \text {, } \\
\text { de 07/12/1929; } \\
\text { - Transformada em Escola Normal Oficial em 1945; }\end{array}$ \\
\hline $\begin{array}{l}\text { Escola Normal Livre Municipal de Santa } \\
\text { Cruz do Rio Pardo }\end{array}$ & $\begin{array}{l}\text { - Criada pelo Município em 1929; } \\
\text { - Transformada em Escola Normal Oficial pelo } \\
\text { Decreto no } 10.336 \text { de 21/06/1939; } \\
\text { - Atual Escola Estadual Leônidas do Amaral Vieira. }\end{array}$ \\
\hline Escola Normal Livre Municipal de Lins & $\begin{array}{l}\text { - Criada em 1929; } \\
\text { - Anexada ao Colégio Diocesano em } 1938 \text { e } \\
\text { denominada Escola Normal Livre N. S. Auxiliadora; } \\
\text { - Atual Colégio N. S. Auxiliadora. }\end{array}$ \\
\hline Escola Normal Livre Municipal de Itápolis & $\begin{array}{l}\text { - Criada pelo Decreto Municipal no } 85 \text {, de } \\
\text { 30/10/1929. }\end{array}$ \\
\hline Escola Normal Livre Municipal de Sorocaba & $\begin{array}{l}\text { - Criada pelo Decreto Municipal no } 209 \text { de } \\
\text { 16/01/1929. }\end{array}$ \\
\hline $\begin{array}{l}\text { Escola Normal Livre Municipal de S. José } \\
\text { dos Campos }\end{array}$ & - Criada em fevereiro de 1930. \\
\hline $\begin{array}{l}\text { Escola Normal Livre Municipal de Moji das } \\
\text { Cruzes }\end{array}$ & $\begin{array}{l}\text { - Reaberta em 27/03/1939, mas sua criação foi em } \\
1930 .\end{array}$ \\
\hline
\end{tabular}

Fontes: Quadro elaborado conforme informações da Poliantéia Comemorativa do Primeiro Centenário do Ensino Normal do estado de São Paulo (1946), O Ensino Secundário e Normal do Estado de São Paulo (1949) e Mascaro (1956). 
O quadro acima mostra que a ação municipal sobre a criação de Escolas Normais Livres foi considerável nas regiões do Vale do Paraíba (Mogi das Cruzes, São José dos Campos e Taubaté), do Norte (Itápolis, Mirassol, Franca, São Simão) e da considerada então, região Oeste, onde se formaram os novos núcleos urbanos.

\section{Considerações Finais}

A Reforma de 1927 possibilitou a expansão do Ensino Normal a fim de ampliar o ensino primário, ou seja, por trás de um projeto de ampliação das Escolas Normais havia também um projeto de ampliação das escolas primárias e, consequentemente, levar o progresso para os novos núcleos urbanos, com a difusão das luzes. É importante destacar que a expansão do Ensino Normal para o interior naquele momento foi uma oportunidade para diversos jovens ampliarem seus estudos e obterem uma profissão. Essas Escolas Normais recebiam alunos oriundos de famílias pobres, que procuravam uma promoção social ${ }^{35}$, e alunos de famílias abastadas que buscavam formação intelectual.

Pela análise das pesquisas sobre as Escolas Normais Livres paulistas, levantamos alguns questionamentos em relação ao processo de expansão do Ensino Normal, pois a criação das Escolas Normais, tanto das Oficiais como das Livres, parece estar imbricada, primeiramente, às relações e aos interesses políticos, com a articulação entre lideranças locais com os poderes estaduais, e em segundo lugar, às necessidades e demandas da população escolar. Nesse sentido, pontuamos serem pertinentes as considerações de Tanuri (1979) sobre o processo de expansão das Escolas Normais ter sido acelerado e desorganizado.

Podemos afirmar com este estudo que o processo de expansão não foi homogêneo em todas as regiões do estado e as características culturais, econômicas e demográficas precisam ser consideradas cuidadosamente, pois a expansão do Ensino Normal pode ter tomado sentidos distintos entre regiões urbanizadas (com cidades antigas e populosas) e regiões ainda em processo de povoamento (novos núcleos urbanos).

Diante dessas transformações no cenário educacional paulista, é importante frisar que esse foi um momento ímpar para expansão do Ensino Normal ao romper com o monopólio do estado e abrir para a iniciativa municipal e particular. Nesse terceiro momento de expansão da formação de professores, a ação municipal teve papel fundamental com a criação das Escolas Normais Livres, mesmo que, inicialmente, na maioria dos casos, elas não tenham tido êxito. Outra questão que precisamos destacar é o interesse por parte da edilidade e dos gestores municipais em prover as escolas com professores devidamente formados, seja, em Escolas Normais Oficiais ou Livres.

Consideramos que na impossibilidade de expandir Escolas Normais do mesmo nível das existentes, os reformadores buscaram manter apenas a superioridade da Escola Normal da Capital, reduzir todas as outras e abrir para a iniciativa municipal e particular para que contribuíssem, de forma voluntária ou involuntária, para a expansão do Ensino Normal. O fato de os professores leigos terem sido exonerados em 1930 demonstra que, ainda que parcialmente, a Reforma de 1927 começou a colher os frutos. Ressaltamos ainda que a Reforma possibilitou a muitos municípios terem uma Escola Secundária, haja vista que os Ginásios eram parcos no Estado de São Paulo.

\footnotetext{
35 Segundo Monarcha (1999), com a reabertura da Escola Normal da São Paulo (1875), ela atraiu cada vez mais alunos, a maioria de origem pobre, que procuravam uma promoção social. Mas com a expansão do Ensino Normal para o interior, os alunos eram de ambas as classes sociais.
} 


\section{Referências}

ALMEIDA, Adriana R. da Mota. Entre o monumento idealizado e o realizado: a Escola Normal Livre Municipal de Sorocaba (1929 a 1967). 2015. Tese (Doutorado em Educação) Universidade de Sorocaba, Sorocaba, 2015.

ALMEIDA, Jane Soares de. A formação de professores em São Paulo (1846-1996): a prática do ensino em questão. Campinas: Autores Associados, 2016.

ANTONIO, M. R. S.; SOUZA, R. F. O Ginásio Municipal e a formação de professores: a Escola Normal Livre Mackenzie de Araraquara (1928-1939). In: SOUZA; R. F.; VALDEMARIN, V. T.; ZANCUL, M. C. S. (Org.). O Ginásio da Morada do Sol: história e memória da Escola Estadual Bento de Abreu de Araraquara. São Paulo: Editora Unesp, 2014, p. 92-103.

AZEVEDO, Fernando de. A educação na encruzilhada. São Paulo: Melhoramentos, 1937.

BRUSCHI, Veralúcia Romanini. A Escola Normal Livre de Itápolis: vozes e imagens (1930-1960). 2005. Dissertação (Mestrado em Educação) - Centro Universitário Moura Lacerda, Ribeirão Preto, 2005.

CAMPOS, Angela B. M. B. de. O curso Normal do Liceu Feminino Santista: a longa busca pela equiparação. 2018. Dissertação (Mestrado em Educação) - Universidade Católica de Santos, Santos, 2018.

CARVALHO, Marta Maria Chagas de. A Escola e A República e outros ensaios. 1. ed. Bragança Paulista: EDUSF, 2003.

CATANI, Denice Barbara. Educadores à meia-luz. Bragança Paulista: Editora da Universidade São Francisco, 2002. v. 1.

CHARTIER, Roger. História Cultural entre práticas e representações. Rio de Janeiro: Berltrand, 1990

CORREIO PAULISTANO. O desenvolvimento da instrução na alta Sorocabana. São Paulo, 16 maio 1930, p. 5.

DINIZ, Carlos Alberto; SOUZA Rosa Fátima de. A colaboração dos municípios na expansão do ensino secundário no estado de São Paulo (1930-1964). In: Cadernos de História da Educação, v.18, n.1, p.93-121, jan./abr. 2019. Disponível em: http://www.seer.ufu.br/index.php/che/article/view/47620/25731. Acessado em 03 jun. 2019. https://doi.org/10.14393/che-v18n1-2019-6

FURTADO, Alessandra C. Por uma história das práticas de formação docente: um estudo comparado entre duas escolas normais de Ribeirão Preto/SP (1944-1964). 2007. Tese (Doutorado em Educação) - Universidade de São Paulo, São Paulo, 2007.

HONORATO, Tony; Nery, Ana Clara Bortoleto. The normal school of Piracicaba as a memory place of the republican regime in Brazil. In: History of education \& children's literature, v. XIV, p. 163-182, 2019. Disponível em: http://www.hecl.it/. Acessado em 26 set. 2019.

INOUE, Leila Maria. Entre Livres e Oficiais: a expansão do Ensino Normal em São Paulo (1927-1933). 2015. Tese (Doutorado em Educação) - Universidade Estadual Júlio de Mesquita Filho, Faculdade de Filosofia e Ciências, Marília, 2015. 
LABEGALINI, Andreia C. F. B. A formação de professores nos Institutos de Educação de São Paulo (1933 a 1945). 2005. Tese (Doutorado em Educação) - Universidade Estadual Paulista Júlio de Mesquita Filho, Faculdade de Filosofia e Ciências, Marília, 2005.

LIMA, Ana Lúcia de Almeida. A educação em Sorocaba - do final do século XIX até a criação da Escola Normal Livre de Sorocaba em 1929. 2005. Dissertação (Mestrado em Educação) - Universidade de Sorocaba, Sorocaba, 2005.

LINS. Lei Municipal $n^{o}$ 67, de 25 de janeiro de 1929. Atas da Câmara Municipal. Lins, 1929. [Manuscrito não paginado]

MASCARO, Carlos Corrêa. O Ensino Normal no Estado de São Paulo: subsídios para estudos da sua reforma. São Paulo: Secção de Publicação da Universidade de São Paulo,1956.

MENDES, Amadeu. Relatório: apresentado ao Secretário do Interior Dr. Fabio de Sá Barreto (1927-1928). São Paulo: Irmão Ferraz, 1929.

MESSENBERG, Cyntia Grizzo. A série Na roça, de Renato S. Fleury, na história do ensino da leitura no Brasil. 2012. Dissertação (Mestrado em Educação) - Universidade Estadual Júlio de Mesquita Filho, Faculdade de Filosofia e Ciências, Marília, 2012.

MONARCHA, Carlos. Escola Normal da Praça: o lado noturno das luzes. Campinas: Editora UNICAMP, 1999.

NASCIMENTO, Lúcia Tavares. A Escola Normal Livre de Santos: uma realização da Associação Instrutiva José Bonifácio. 2016. Dissertação (Mestrado em Educação). Universidade Católica de Santos, Santos, 2016.

NERY, Ana Clara B. A Sociedade de Educação de São Paulo: embates no campo educacional (1922-1931). São Paulo: Editora Unesp. 2009. https://doi.org/10.7476/9788539304509

O ENSINO SECUNDÁRIO E NORMAL DO ESTADO DE SÃO PAULO (1949). São Paulo: Instituto de Administração da Faculdade de Ciências Econômica e Administrativas da Universidade de São Paulo, 1949.

O ESTADO DE S. PAULO. Dispensa dos professores leigos. São Paulo, 30 nov. 1930, p. 4.

O LINENSE. Nota sobre a Escola Normal Livre de Lins. Lins, 14 maio 1928, p. 1.

PERES, Tirsa Regazzini. O advento da Escola Normal Livre e seus resultados comparados com os da Normal Oficial (1927-1930). Araraquara, 1966. Mimeo.

PRADO, Celso; SATO, Junko. Santa Cruz do Rio Pardo: memórias, documentos e referências. 2013. Disponível em: <http://satoprado.ebook.blogspot.com.br/2013/07/escolaspioneiras.html>. Acesso em: 05 jun. 2019.

RODRIGUES, João Lourenço. Livro Jubilar da Escola Normal da Capital: contendo a relação completa de diplomados de todos os institutos congêneres do Estado de São Paulo (1897-1929). São Paulo: Instituto D. Ana Rosa, 1930. 
SANDANO, Wilson. A criação da Escola Normal Livre de Sorocaba. Série-Estudos Periódico do Mestrado em Educação da UCDB. Campo Grande, n. 28, p. 75-87, jul./dez. 2009. Disponível em: http://www.serie-estudos.ucdb.br/index.php/serie-estudos/article/view File/177/264. Acesso em: 25 maio. 2019.

SANTA CRUZ DO RIO PARDO. Lei Municipal n. 429, de 25 de agosto de 1928. Ata da Câmara Municipal, Santa Cruz do Rio Pardo, 1928. [Manuscrito não paginado]

SÃo PAUlO. Annuário do Ensino do estado de São Paulo. São Paulo: Augusto Siqueira \& C., 1918.

SÃO PAULO. Decreto $n$. 2269, de 31 de dezembro de 1927. Disponível em: <http://www.al.sp.gov.br/repositorio/legislacao/lei/1927/lei-2269-31.12.1927.html>.

Acesso em: 10 jun. 2019.

SÃO PAULO. Decreto $n^{o} 4.600,30$ de maio de 1929. Disponível em: https://www.al.sp.gov.br/repositorio/legislacao/decreto/1929/decreto-4600-30.05.1929.html.

Acesso em: 26 jun. 2019.

SÃO PAULO. Decreto $n^{o}$ 4.794, de 17 de dezembro de 1930. Disponível em: <http://www.al.sp.gov.br/repositorio/legislacao/decreto/1930/decreto-4794-17.12.1930.html>. Acesso em: 28 jun. 2019.

SÃO PAUlO. Annuario do Ensino do estado de São Paulo. São Paulo: Typographia do Diário Official, 1935-1936.

SÃO PAUlO. Poliantéia Comemorativa do Primeiro Centenário do Ensino Normal do estado de São Paulo. São Paulo: Gráfica Bréscia,1946.

SOUZA, Rosa Fátima de. Alicerces da Pátria: história da escola primária no estado de São Paulo (1890 - 1976). Campinas: Mercado de Letras, 2009.

TANURI, Leonor Maria. A Escola Normal no Estado de São Paulo no período da Primeira República: contribuições para o estudo de sua estrutura Didática. 1973. Tese (Doutorado em Educação) - Unesp, Marília, 1973.

TANURI, Leonor Maria. O Ensino Normal no Estado de São Paulo (1890-1930). São Paulo: FEUSP, 1979.

TREVISAN, Thabatha Aline. A Pedagogia por meio da Pedagogia: Teoria e Prática (1954), de Antonio d' Ávila. 2007. Dissertação (Mestrado em Educação) - Faculdade de Filosofia e Ciências, Unesp-Marília. 2007. 